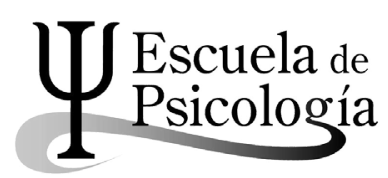

Wímb lu, Rev. electrónica de estudiantes Esc. de psicología, Univ. de Costa Rica. 10 (2): 67-75, 2015 / ISSN: 1659-2107

\title{
DISCRIMINACIÓN SOCIAL: ANÁLISIS DE DOS CASOS DE TRABAJADORES MIGRANTES NICARAGÜENSES
}

\author{
Social discrimination: analysis of two cases \\ of Nicaraguan migrant workers
}

Marco Rojas Lizano*

\begin{abstract}
Resumen: Las complejas dinámicas sociales y de mercado empujan a las personas a buscar mejores condiciones de vida en contextos que no siempre se constituyen en los mejores escenarios para el desarrollo personal. La migración de personas nicaragüenses hacia Costa Rica se ha convertido en un fenómeno el cual urge estudiar desde una psicología crítica. El presente artículo trata de abordar las experiencias de dos trabajadores nicaragüenses residentes en el cantón de Naranjo de Alajuela, en torno al tema de la discriminación social a la que se han visto expuestos desde su llegada al país. Se abordan los motivos y formas de migración, redes de solidaridad, condiciones laborales y acceso a servicios públicos.
\end{abstract}

Palabras clave: migración, discriminación social, nicaragüenses.

Abstract: Market and social dynamics push people forward to look for better living conditions under contexts that are not always the most appropriate for personal development. Nicaraguan people's migration to Costa Rica has become a phenomenon which that needs to be studied with urgency under the scope of critical psychology. This article attempts to approach the experiences of Nicaraguan workers currently living in the canton named Naranjo of Alajuela, regarding the social discrimination they have been exposed to since their arrival to this country. The reasons and ways of migration, social security networks, working conditions and access to public services are approached in this document.

Key Words: Migrations, social discriminations, nicaraguan people.

Universidad de Costa Rica. Egresado Escuela de Psicología. Costa Rica.

Correo: maizerojas@gmail.com.

Recepción: 29/12/2014 Aceptación: 3/8/2015. 
"Soy un inmigrante del mundo mundial, indocumentado un ser espacial, soy gente de gente que cruza fronteras que intenta de nuevo volver a empezar" Perrozompopo, Ríos de Gente

\section{Introducción}

Para el entendimiento de los procesos migratorios de nicaragüenses hacia Costa Rica a finales del siglo XX y a inicios del XXI, se debe recordar los procesos socio históricos de revoluciones armadas que fueron vividas en América Latina como respuesta a extensas y crueles dictaduras que azotaron poblaciones, generando condiciones de vulnerabilidad especialmente para las clases bajas.

En el caso específico de Nicaragua, con la conformación del Frente Sandinista de Liberación Nacional, se inicia un proceso revolucionario para el derrocamiento de la dinastía de los Somoza quienes se instituyeron en el poder y control de este país por más de cuarenta años.

Dicho conflicto armado, el cual fue seguido (o prolongado) en la década de los ochentas e inicios de los noventas, por las políticas intervencionistasanticomunistas de Estados Unidos que financiaron la contrarevolución, empobreció aún más al país, ocasionando, entre muchos otros motivos, la movilización de personas hacia países como Costa Rica y Honduras, en busca de mejores condiciones de vida.

Con la llegada de esta población a lo largo de estos años, se han generado a la vez procesos de discriminación como respuesta al sentimiento de amenaza que el otro diferente constituye para la población de la sociedad que recibe al migrante (López y Pernudi, 2013), en este caso, la costarricense. Sin embargo estos procesos de discriminación y xenofobia (Dobles, Vargas y Amador, 2014) no solo son realizados por la población civil, sino que también pasan por la acción del Estado, incapaz de hacer frente a las necesidades de estas personas que también habitan en el territorio nacional.

Ejemplo de lo que se ha mencionado, en el XX Informe del Estado de la Nación, se menciona la cantidad de personas trabajadoras que no cuentan con ninguna cobertura por parte del seguro de la Caja Costarricesense del Seguro Social (CCSS). Se menciona un total de 56140 trabajadores agrícolas, 39176 de la construcción y 32136 del servicio doméstico, labores que típicamente son desempeñadas por las personas migrantes nicaragüenses a la hora de ingresar a Costa Rica en busca de condiciones de vida mejores a las que tenían en su país. Según los datos presentados en el informe citado, la condición de hombre migrante joven, coloca a la personas en situaciones de mayor vulnerabilidad en 
cuanto a la seguridad social con respecto a la salud, lo cual compromete las garantías laborales que rigen en Costa Rica.

Ante esta realidad, se evidencia la falta de políticas públicas con respecto al tema de la población migrante que acompañe, dialogue y proponga espacios de análisis de las actuales leyes que intentan regir la estancia y dinámica de las personas migrantes, en este caso en particular, nicaragüenses.

Justamente en este análisis surge el espacio de desarrollo de la práctica profesional del Módulo de Psicología de los Procesos de Discriminación Social de la Universidad de Costa Rica $(\mathrm{UCR})^{1}$ en colaboración con la incipiente pero fuerte organización de migrantes trabajadores y trabajadoras que residen en el cantón de Naranjo de Alajuela. Dicho acercamiento consistió en la realización de entrevistas semiestructadas, las cuales permitieron profundizar en las vivencias en torno a la discriminación laboral que se sufre al ser migrante en Costa Rica. A la vez el rescate de estas experiencias y su análisis integral, tienen la intensión de ser denuncia de una realidad nacional. Es por esto la metodología cualitativa funge como posibilitadora de dar espacio a la significación de lo singular en la creación del conocimiento (Gonzáles Rey, 2008), además responde al interés de trabajar y construir una psicología crítica, que como menciona Gonzáles Rey (2008) haciendo alusión a la obra de Martín Baró, debe de ser capaz de entender, elaborar y actuar sobre realidades las cuales pretende transformar.

En este artículo se presenta un análisis de casos anónimos cuyos participantes fueron dos hombres trabajadores migrantes procedentes de Nicaragua, a quienes por confidencialidad de la información se les ha cambiado el nombre. Dichos casos son abordados a la luz de las evidencias encontradas por otros y otras investigadoras, sobre el tema de migración de nicaragüenses hacia Costa Rica, en el cual tiene como áreas de estudio: motivos y forma de migración, redes de solidaridad, condiciones laborales y acceso a servicios públicos.

\section{Migración: el viaje}

En el estudio de los casos de estas dos personas nicaragüenses, se encuentra una similitud ante las motivaciones que dieron paso a la movilización desde su país natal, Nicaragua, hacia Costa Rica. La búsqueda de mejores condiciones de vida, reflejadas en su discurso como mejores condiciones laborales y económicas, fueron las que llevaron a ambos a emprender el viaje. Por su parte Carlos, indica que las condiciones laborales en su país no eran las mejores:

Diay, por un lado, eh, las circunstancias de labores de trabajo, eh, muy poco, el salario bastante bajo... porque nosotros aquí, eh, en Costa Rica, venimos a trabajar, por decirlo así. En mi caso yo vengo, yo vine de muchos circunstancias, no porque 
yo sea malo, porque yo me vine bien de allá, no, sino que para sacar adelante a mi familia (...) diay, a la cuenta a hacer plata, a trabajar y diay, no se ha hecho nada.

Actualmente para Luis se presenta una situación más difícil, pues a diferencia de José, este se encuentra desempleado.

En estos dos casos los viajes se realizaron de manera irregular o como lo menciona Luis, "ilegal". Tanto Luis como Carlos realizaron el viaje acompañados y conocían de las experiencias previas de otras personas que habían tomado la determinación de trasladarse hacia Costa Rica. Esta situación Borge (2005) la denomina como medios de comunicación que permiten a las personas nicaragüenses que aún están en su país de origen, tener conocimiento acerca de oportunidades laborales en el país receptor. En el caso de Luis, se puede evidenciar que estos medios de comunicación, además sirvieron para conocer estrategias de entrada al país de manera "ilegal", esto reflejado en la figura de su primo que ya había tenido la experiencia previa de cruzar la frontera.

El conocimiento de experiencias previas pareciese un motivo fuerte a la hora de tomar la decisión de realizar la migración, pues dicha información da orientaciones de los pasos a seguir para el alcance del objetivo: llegar a Costa Rica a trabajar, el cual logran cumplir.

\section{Redes de Solidaridad (Redes sociales)}

Los medios de comunicación mencionados en el apartado anterior, forman parte de una estructura más grande que son las redes de solidaridad (Redes Sociales para Borge, 2005). Estas redes responden a la necesidad de los migrantes recién llegados para la búsqueda tanto de empleo como de un lugar donde quedarse mientras comprenden la dinámica del país que los recibe.

En el caso de Carlos, tras su llegada, se pudo ubicar con su compañera e hijo en Turrialba, en la casa de los familiares de ésta: "...la familia de la doña vive en Turrialba. De una vez a Turrialba y de Turrialba hicimos contacto aquí a Naranjo y ya nos vinimos pa'cá.". De esta manera no solo consiguió posada y trabajo a la hora de su llegada, sino que tras terminado su primer trabajo en Costa Rica, la recolección de café, también se pudo vincular con otras personas ubicadas en Naranjo de Alajuela, lo cual le permitió seguir con su objetivo de buscar mejores condiciones de vida.

El caso de Luis tiene una particularidad interesante y es el hecho de recibir ayuda por parte de otras personas nicaragüense quienes se encontraban en las mismas condiciones de vulnerabilidad. Esto se da a la hora que le deportan hacia Nicaragua, sin tener dinero para poder trasladarse para ninguna otra parte: 
me llevaron al puesto, ahí pega con el otro puesto nica, ahí me llevaron ahí a entregar, desde ahí están las busetas nicas que van a dejarlos a la ciudad de San Carlos de Nicaragua... de San Carlos yo estaba muy aburrido porque, diay, sin plata, los únicos mil, los descambié y me los comí en algo...y ahí quedé sin plata, y este, unos conocidos que andaban, casualmente iba otro muchacho, también inmigrante que ese si es de ahí de San Carlos, de San Carlos Laureles y, y allí nos asociamos, la jugamos y bueno, él llegó donde la familia y consiguió plata y bueno, nos vinimos a trabajar.

En la situación anteriormente narrada parece existir una doble vía de beneficio dentro de esta red de solidaridad, a la hora de que se les es deportados hacia Nicaragua, Luis es ayudado económicamente para trasladarse de nuevo a Costa Rica, mientras que el conocido que le ayuda, emprende el viaje de regreso acompañado lo cual puede significar un apoyo en caso de que las circunstancias pudiesen empeorar.

Dichas redes de solidaridad significan estrategias de sobrevivencia y protección ante contexto políticos y sociales adversos para personas que son percibidas como una amenaza y competencia (Dobles, Vargas y Amador, 2014).

\section{Trabajo y acceso a servicios de Salud}

Como se mencionó, uno de los principales trabajos desarrollados por migrantes nicaragüenses hombres en Costa Rica es el de la agricultura. Ante esto Castro (2002) propone que dicha realidad se puede deber a las estructuras de inserción laboral de Nicaragua, en donde para el año del 2002, la mayor área de empleo era en el sector primaria, dígase la producción agrícola.

Tanto para Carlos como para Luis, dentro de su experiencia en Costa Rica, sus trabajos en varios momentos han sido la agricultura. En este momento Carlos se define como un operario agrícola. Dicha ocupación la aprendió en su país de origen, de igual manera Luis. Sin embargo, pese a que han estado vinculados a labores agrícolas, también en este país han aprendido oficios como el de la construcción, en el caso de Carlos quién lo cuenta de la siguiente manera:

lo que es construcción, lo vine a aprender aquí a Costa Rica. Le agradezco un montón y mucho, sí claro, trabajé con muy buenos maestros de obras entonces uno como un peón, por decirlo así, yo entré como ayudante, después ya como operario, calidad, a pegar cerámica, a repellos, cielorasos, bueno, eso, aquí lo aprendí.

Ante la llegada y la inserción en el área laboral, ya sea de manera regular o irregular, las personas migrantes son identificados con una serie de percepciones que tienen los costarricenses para estas personas, los cuales en muchos casos llegan a ser discriminatorias (ver López y Pernudi, 2013). Dentro de estas percepciones se piensa que los nicaragüenses vienen a robar el trabajo que podría 
estar ocupando una persona costarricense. Carlos expresa esta realidad con el siguiente relato que refuerza las percepciones de unos y otros:

...a veces yo he hablado muchos términos así, hemos estado con muchos, bueno yo en mi caso, con muchas amistades y lo primero que a mí me dicen es "Carlos, te voy a ser claro, pero es que ustedes los nicaragüenses a veces se vienen, eh, a robar el salario de uno, porque si ustedes no hubieran venido aquí, nosotros estuviéramos a cachete", y yo digo "nómbrele, tranquilo, ¿sabés que es lo que pasa?, son dos cosas diferentes, nosotros venimos a trabajar por una cosa, por otro, nos gusta el trabajo porque desde chiquitillos nos enseñaron y por otro lado que ustedes son vagos, ya, ustedes son vagos." "aaah, dijiste la verdad".

Según lo planteado por Dobles et al (2014) en este tema existe una contradicción en el posicionamiento de la función de la persona migrante nicaragüense en la sociedad costarricense, pues por un lado existen posturas como la que narra Carlos en el párrafo anterior, también existen demandas de mano de obra extranjera por parte de grupos empresariales, que pueda suplir la escasez de esta por parte de los nacionales.

Esta demanda de mano de obra da pie a que se den agresiones a los derechos humanos y procesos de discriminación y explotación laboral de las personas trabajadoras migrantes, esto siguiendo la línea de la creación de ejércitos industriales de reserva (Marx, 1985, citado por Navarro, 2013), quienes ante la posibilidad de contratar a cualquier migrante aprovechándose de su necesidad de trabajo, se manejan al margen de los derechos laborales con la amenaza de despido. Ejemplo de esto es lo vivido por Luis:

Bueno estuve trabajando en un lugar que, en un aserradero, donde un patrón en Coopevega...El lugar, de ahí me vine, bueno, estuve allá, eh, y el patrón se puso en varas, no me quiso pagar una plata, eh, y este, se puso enojado y yo le dije que me venía y me echó migración y no me pagó.

A esta situación se le suman otras agresiones en cuanto al tema de acceso a la salud vinculados al ámbito laboral. Luis cuenta la situación que vivió ante una cortada sufrida en el trabajo:

Bueno un día que estuve trabajando, aquí, en Naranjo, me había cortado y me, y me corté como a las nueve y me dijeron que me iban a pagar el día. Ni el día me pagaron, ni los días que estuve cortado, nada... me llevaron al EBAIS ${ }^{2}$ me cosieron... pero tenía que pagar pero como no tenía plata solo me cosieron y bueno, ya, me la jugué.... [El patrón le aconseja decir] me aconsejó que no le estaba ayudando a nadie, que yo me había cortado solo, que iba en el camino y yo le estaba ayudando al patrón.

Continuando con el tema del acceso al servicio de salud pública, en el caso de Carlos, tras veinte años de intermitentemente cumplir con las cuotas al seguro de la CCSS, no puede cubrir a su compañera con este por la falta de una cédula 
de residencia, pese a que su compañera depende económicamente de él pues no tiene otros ingresos económicos.

\section{Efectos psicosociales de la discriminación}

Es importante rescatar los efectos psicosociales que estos mecanismos de discriminación han generado en estas personas. En el caso de Carlos y consecuente con lo que plantean Fryberg y Townsend (2008), parece existir cierta angustia ante la posibilidad de que se le encasille dentro del estereotipo negativo que en el imaginario costarricense, se tiene sobre los nicaragüenses:

Pero sí, somos discriminados, somos discriminados, nosotros los nicaragüenses somos, por ciertas personas, equis motivo, qué sé yo, y yo creo que no debe ser así, nosotros somos seres humanos y yo creo que nos merecemos respeto, nos merecemos que nos apoyen, por decir así, si venimos derrotados, sí, somos hijos de dios, somos seres humanos que nos merecemos, somos y ya ves, somos discriminados pero las cosas son así y alguien tiene que pagar algo, por algo que hizo, son los gobiernos, son los presidentes, eh, ya son la política, ya es, ya se está hablando de plata, y nosotros los pobres siempre tenemos que salir a emigrar.

Otro de los efectos percibidos es la humillación ante tratos inhumanos, en donde la persona pasa a ser un bien de producción desechable y sustituible por otra persona en las mismas condiciones. Las personas se llegan a sentir humilladas antes estas situaciones, como Carlos cuenta: "yo tengo muchas cosas que hablar, lo que pasa es que uno a veces, o sea, es muy educado y diay, gracias porque, diay, uno está en otro país también, y uno a veces se humilla, se humilla, por, porque diay, así tiene que ser". Esto resultado de las condiciones laborales en las que se encuentran las personas migrantes y que las leyes actuales se quedan cortas para enfrentar ${ }^{2}$.

\section{Conclusiones}

Esta organización de trabajadores y trabajadoras de personas migrantes en Naranjo, tiene la importancia de acompañar en la demanda de la garantía de los derechos humanos de estas personas, tratando de generar un dialogo que permita la transformación de las estructuras de entendimiento de los fenómenos migratorios y a la vez de las legislaciones y políticas, en el caso de que lleguen a existir.

La realidad es muy compleja para las personas nicaragüenses que buscan en Costa Rica mejores condiciones de vida, en especial cuando su permanencia 
en el país está condicionada por leyes carentes del acompañamiento de políticas públicas que en realidad busquen eliminar los procesos de discriminación.

Dicha discriminación pasa por la violencia estructural la cual nos limita en el desarrollo de nuestras potencialidades (Solano, 2005) y se gesta en la lógica de mercado que convierte a las personas en mercancía o en un mecanismo para lograr riqueza sin importar su condición humana.

A esto se le suma un Estado cómplice, incapaz de hacerle frente a una realidad que día a día agrede los derechos inherentes a cada persona. Los intentos fallidos por generar legislación que respete la integridad y los derechos históricos de las personas (reflejada en la Ley de Migración y Extranjería 8764 del 2009) se evidencia además en la invisibilización de la realidad migrante indocumentada que se vive en nuestro país y como estas personas a la vez están cumpliendo con roles sociales enmarcados en imaginarios discriminatorios.

Los relatos de Carlos y Luis dan un breve acercamiento a la realidad, que podríamos pensar, es compartida por muchas personas más dentro de estas formas de ordenamiento mundial, en donde la interseccionalidad (Lugones, 2005) de condiciones agudizan la discriminación y exclusión. Condiciones como etnia, nacionalidad, género. Y es esta última condición, la de género, que se constituye como un pendiente a investigar con el grupo de trabajadores y trabajadoras de Naranjo.

La organización de estas personas, permitiéndose encontrar realidades semejantes a las vividas, constituye un foco de resistencia ante las acciones discriminatorias. El sentimiento de pertenencia a un grupo estando lejos de su país y familia, permite a la vez resignificar sus experiencias a la hora de ofrecer apoyo a personas que necesitan de orientación a la hora de llegar al país. La organización como tal, resulta una necesidad para esta parte de la población del país, como lo dice José: "...me gustaría que viera que sí, este, se mueva más y se organice más, diay, los perjudicados somos nosotros los trabajadores y el de corbata y el de plata yo creo que no, él está completo".

\section{Notas}




\section{Referencias}

Borge, D. (2005). La fuerza de los vínculos débiles en la inserción laboral de los migrantes nicaragüenses. Población y Salud en Mesoamérica, 3 (1), 1-16. Recuperado desde revistas.ucr.ac.cr/index.php/psm/article/ download/4569/4384

Castro, C. (2002). Informe sobre inserción laboral y remesas de los migrantes nicaragüenses en Costa Rica. En Redes transfronterizas: sociedad, empleo y migración entre Nicaragua y Costa Rica. Recuperado desde http://biblioteca. clacso.edu.ar/ar/libros/costar/redes/red1.pdf

Dobles, I., Vargas, G., \& Amador, K. (2014). Inmigrantes. Psicología, Identidades y Políticas Públicas. La experiencia nicaragüense y colombiana en Costa Rica. San José, Costa Rica: Editorial de la Universidad de Costa Rica.

Fryberg, S y Townsend, S. (2008). The Psychology of Invisibility. En: Adams, G; Biernat, M ; Branscombe, N; Crandall, C y Wrightsman. Conmmemorting Brown the social Psychology of Racism and Discrimination. Wasington. American Psychology Association.

Gonzáles Rey, F. (2008). Subjetividad y psicología crítica: implicaciones epistemológicas y metodológicas. En Subjetividad, Participación e Intervención Comunitaria. Buenos Aires: Paidos.

López, L y Pernudi, V. (2013). Prejuicios y actitudes de los costarricenses hacia los migrantes nicaragüenses. En Psicología de la Liberación en el contexto de globalización neoliberal. San José, Costa Rica: Editorial de la Universidad de Costa Rica.

Lugones, M. (2005) Multiculturalismo radical y feminismos. Revista internacional de filosofía política, 25, p 61-76 .Recuperado desde http://dialnet.unirioja.es/ servlet/ejemplar?codigo $=116762$

Navarro, S. (2013). Turismo y inmigración en la Playa Matapalo, Sardinal, Costa Rica. Resistencias comunitarias y laborales. Anuario de Estudios Centroamericanos, 39, 263-287. Recuperado de http://revistas.ucr.ac.cr/ index.php/anuario/article/view/11807/11129

Solano, M. (2005). Capitalismo y Violencia. Intersedes: Revista de las Sedes Regionales, 126 (10-11), 1-25.

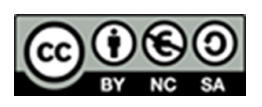

Esta obra está bajo una licencia de Creative Commons Reconocimiento

- NoComercial - CompartirIgual (by-nc-sa) 